Universidad de Lima

Facultad de Comunicación

Carrera de Comunicación

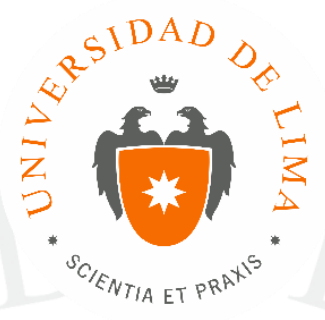

\title{
SOBRE LA DINÁMICA INTERACTIVA Y EL HACINAMIENTO DE LOS VIAJEROS EN DOS LÍNEAS DE BUSES DE LIMA
}

Trabajo de investigación para optar el Título Profesional de Licenciado en

Comunicación

\section{Christopher Dante Rojas Quispe \\ Código 19971485}

\section{Asesor}

Julio Guillermo Hevia Garrido Lecca

Lima - Perú 


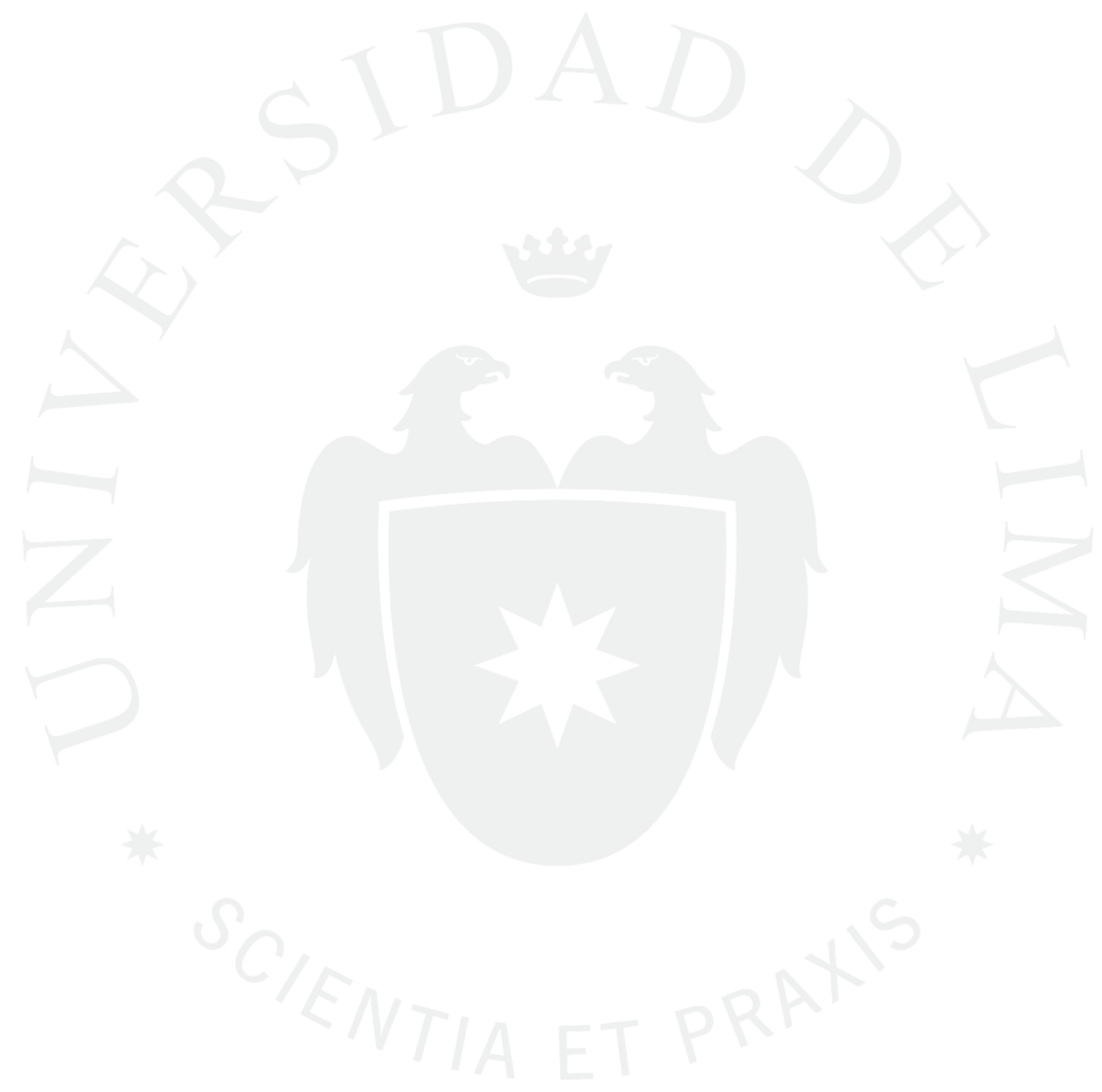




\section{SOBRE LA DINÁMICA INTERACTIVA Y EL HACINAMIENTO DE LOS VIAJEROS EN DOS LÍNEAS DE BUSES DE LIMA}




\section{ÍNDICE GENERAL}

Introducción

1. Conceptos generales

$\begin{array}{ll}\text { 1.1 Definiciones: Lleno vs vacío } & 7\end{array}$

1.2 Dinámicas: repliegues, distensiones 9

1.3 Flâneur y voyeur 11

2. Personajes $y$ performances

$\begin{array}{ll}2.1 \text { El mendigo } & 13\end{array}$

$\begin{array}{ll}2.2 & \text { El delincuente }\end{array}$

$\begin{array}{ll}2.3 \text { El mañoso } & 16\end{array}$

$\begin{array}{ll}2.4 \text { El viajero - estándar } & 19\end{array}$

3. Delimitando campos de acción

$\begin{array}{ll}3.1 \text { Callao city } & 21\end{array}$

3.2 Lima Centro 26

$\begin{array}{ll}\text { Conclusiones } & 30\end{array}$

$\begin{array}{ll}\text { Referencias } & 32\end{array}$ 


\section{INTRODUCCIÓN}

En nuestro medio el ensayo es un formato que siempre ha generado ciertas reticencias y suspicacias por el ala academicista más conservadora, no solo por su estilo transgresor y libre, sino también por los parámetros flexibles de los que goza. A su vez, la temática etnográfica urbana se encuentra en las antípodas de una investigación metodológicamente aceptable y supuestamente objetivante de lo observante.

Dicho esto cabe preguntarse por el sentido del presente ensayo y la pertinencia de su elaboración. En primer lugar, no existen estudios que registren lo que ocurre dentro del bus, solo se cuenta con datos estadísticos, pues la data observada se da por sentado y en esa medida carece de importancia reflejarla. Segundo, las dos líneas de buses elegidas, la 87 y la 45, son las más antiguas y aún vigentes en la capital que se desplazan desde el corazón del Callao hasta San Juan de Lurigancho. Tercero, el Callao y Lima Centro son los distritos más antiguos de la capital, caracterizados predominantemente por particularidades invisibles y notorias, en claro contraste con el resto de distritos. Cuarto, los dos buses mencionados resultan predilectos, aunque no exclusivos, para la performances respectivas de los actores sociales mencionados y catapultar así, un desempeño efectivo, esto es, la colaboración, de ahí que la circulación mendicante sea mayor en la 45 y en la 87. Y por último, se trata de un reclamo justificado frente al formato del ensayo como un tipo de trabajo que con toda razón merece un lugar y mayor difusión en el ámbito académico.

$Y$ bien, al tratarse de un trabajo que cae dentro de la microsociología, la influencia de Erving Goffman, Georg Simmel, Isaac Joseph y Philippe Bourgois fue inevitable, aunque también subyace a todo el texto una clara vena deleuziana.

La observación propiamente dicha tomó alrededor de dos años, entre el 2015 y el 2017, y la metodología se inscribe en la sociología reflexiva inaugurada por Pierre Bourdieu, de ahí que se haya llevado a cabo una participación observante, caracterizada por una mayor negociación e intervención del observador, asumiendo postas, embragues y desembragues que reflejen de una manera más cabal, vía la vivencia, lo observado. 
A lo largo del trabajo entonces notarán un análisis constante desde el corazón mismo de la observación, así, son las categorías y definiciones surgidas desde el terreno mismo las que interpelan al lector y promueven una lectura activa y no pasiva, son las grietas de la propia naturaleza de lo observado, los limites que toda participación observante conlleva y lo complejo de reflejar una realidad siempre en movimiento, lo que hará las veces de puntales de acceso al texto.

El trabajo está dividido en tres segmentos. El punto de partida son nociones más o menos fijas que sirvan de soporte para el surgimiento de las categorías de la segunda parte, las cuales darán paso a un zoom out que permita tener un plano general de lo analizado y reverberar aquello que podría haber sido omitido en la primera y segunda parte, así como presentar matices dentro de ellas.

La propuesta es simple, la ciudad en constante movimiento se desplaza y asciende al bus, donde los personajes, transeúntes y dinámicas comunicacionales tendrán lugar, allanando raíces étnico geográficas constantes, apelando al momento, reaccionando; suerte de laboratorio social que refleja cuan esquizofrenizante resulta la experiencia de viajar en bus, reflejada en la comunicación y las estrategias elaboradas al paso para salir bien librado. Dinámicas que luego volverán a la calle, a la urbe, metamorfoseadas para instalarse nuevamente en la ciudad aunque con cuotas novedosísimas y mutantes. 


\section{Conceptos generales}

\subsection{Definiciones: Lleno vs vacío}

Llenar y vaciar la unidad de transporte es un elemento en el cual convergen los intereses del conductor y los usuarios. No obstante, mientras el primero precisa exacerbar su llenado y vaciado, los segundos se enfocan en lo último. Acción llevada a cabo por ese operador particular que es el cobrador. Recordemos que es él quien desciende e insta a los pasajeros a juntarse.

Son las ocho de la mañana, se coloca a la altura de ellos y les grita desde afuera a través de las ventanas: "Señorita, señor, joven, señora, apéguese, todos queremos llegar rápido, para irnos directo, colaboren pues". Y las respuestas no se hacen esperar, "avanza oye tortuga", "crees que estás llevando bultos, animales". Pero los cobradores insisten: "rojo muévase, joven de camisa, señor de mochila, mochila adelante por favor" al tiempo que con su mano derecha hace un ademán e indica así moverse hacia la izquierda. Luego agrega: “baja atrás, baja atrás oe, Salaverry, Arequipa, todo Abancay, todo Abancay".

Hay que tomar en cuenta que la situación anterior es cosa de todos los días, pero también debemos recalcar que el incremento del combustible conllevó un alza en el precio de los pasajes, siempre recibida con desagrado por los pasajeros, medida insuficiente que obligó a los propietarios de los vehículos a maximizar los espacios. Vemos pues el sobredimensionamiento del espacio, más gente cabe en la misma estructura física a través de más asientos, los usuarios son obligados a ingeniárselas para caber en ellos, aunque eso suponga cuotas de incomodidad inevitables.

Una variante de lo vacío se refleja en los buses medianamente llenos de pasajeros sentados y de pie. Ellos, efectivamente, ocupan una porción del espacio físico del bus, hombros caídos, recostados sobre las ventanas, las manos sobre el mentón o la frente, las piernas laxas, la falta de movimiento. Los que están sentados miran a través de los cristales, en ocasiones recuestan la cabeza sobre ellos, observan las calles y a los peatones, al llegar a una parada prestan especial atención a lo que ahí se encuentran. Por 
momentos mantienen la mirada fija hacia adelante. Los que están de pie también la dirigen al exterior, nadie mira hacia el techo o al piso, ni al botiquín ausente o en mal estado, tampoco al extinguidor vencido, mucho menos al mensaje con el número telefónico de la empresa en caso haya alguna queja.

Todo lo anterior evidencia grados de abstracción, líneas de fuga creadas por el propio usuario que requiere el llenado y vaciado constante. El usuario vuelve en sí al ser interpelado con la clásica frase "pasajes, pasajes". El pasajero le da un sol cincuenta. “¿Hasta dónde vas, papi? Manco Cápac. Dos soles, dos soles! ¿Dos soles? Sol cincuenta me cobran todos los días. Dos soles, sino le gusta tómese otro carrito". Luego vuelven a su catatonia, cuando no a la mirada escapista. En suma, es la propia condición de encierro lo que proyecta a los pasajeros más allá de los propios límites del bus, dejándolos ausentes.

La saturación de los espacios también debe ser entendida como el impacto generado entre los interactuantes, ya no entra a tallar el acortamiento o ensanchamiento de la distancia entre ellos y nosotros, vale decir, la proxemia ejercida y cómo ésta es percibida (Hall, 1963). Un sujeto con el rostro, brazos y piernas tatuadas arremete sobre la 45, ha cubierto sus cicatrices con tatuajes, se detiene al frente, un segundo ocupa la parte de atrás; son casi las diez de la noche, la avenida La Marina está libre, hay asientos vacíos, algunas parejas, chicas y chicos solos, iluminación en clave alta. "Mi compañero y yo hemos venido a pedir su colaboración, no queremos estar arranchando carteras en la calle, queremos hacer la cosas bien, ya cometí errores y ya los pagué". No hay música, solo se oye el ruido del tráfico y su voz estridente. "Cualquiera comete errores, hasta un presidente Alberto Fujimori estuvo preso, no me des la espalda ¿si tu hermano está en la cárcel no lo ayudarías?" Camina de adelante hacia la parte posterior y estira la caja de golosinas hasta rozar los rostros de los pasajeros, éstos evitan mirarlo, niegan con la cabeza, al tiempo que escuchan "colabóreme, pe". Pocos hacen efectiva su colaboración y mientras avanza levantando la voz, como quien infunde temor, le dice al otro "mare mano, después se quejan cuando estás en la esquina y le pones un cuchillo, baja atrás". Huyen raudos del bus. 
En los tres casos expuestos podemos decir que el espacio físico no está constreñido por sus límites tangibles, sino por todo aquello que surge del uso del transeúnte, factores imaginarios y personales. Es decir, son los pasajeros quienes al vincularse definen el espacio-bus (Simmel, 1986). En ese orden de reflexión, no es en ninguna medida la proximidad o distancia espaciales las que producen los fenómenos de vecindad o extranjería, sino más bien lo que podemos sentir y percibir. Para decirlo en otra clave, la clásica dualidad cerca - lejos se modifica por el tipo de vínculo entre los agentes, así, podríamos estar cerca a alguien y sin embargo sentirnos completamente distantes y en el otro extremo, lejos de alguien, y a pesar de eso sentirnos cercanos a ellos.

\subsection{Dinámicas: repliegues, distensiones}

El transporte en Lima se erige como una de las cumbres de nuestra cultura, el sistema informal imperante data de la década de los sesenta y responde como manifestación sociológica, por un lado, a la ausencia de un plan por parte del gobierno de turno para hacer frente a la ola migratoria de aquel entonces $y$, por otro lado, al devenir desbordante de lo urbano como categoría itinerante.

Durante las décadas de los 60, 70 y 80 y debido al centralismo cada vez más desbordante de Lima, la exacerbación y el paulatino colapso del parque automotor, así como el calvario experimentado por los usuarios se hizo evidente. Ya en los 90, la creciente demanda de transporte y la ligereza del gobierno de turno al dar carta libre a los propietarios de las llamadas "combis", potenciaron el efecto multiplicador iniciado décadas anteriores.

En efecto, entre 1961 y 2007, la población en Lima y en el Callao aumentó de 2,031,051 a 8,445,211 y de 213,540 a 876877 respectivamente (INEI. Censos Nacionales de Población y Vivienda, 1940, 1961, 1972, 1981, 1993 y 2007). A su vez, de 1972 a 1993, la población migrante del interior a Lima, pasó de 1,512,093 a 2,492,367 (INEI. Censos Nacionales de Población 1972 y 1993). Paralelamente, el $70 \%$ 
de limeños utiliza transporte público (buses, combis, coasters y corredores complementarios) para desplazarse de un lugar a otro, asimismo ese público permanece en promedio 105 minutos al día a bordo de uno o más de éstos, es decir, suman un total de dos años de su vida viajando. (Ipsos Perú, 2015)

Es por eso que el bus es un enclaustramiento sino deliberado, por lo menos inevitable para desplazarnos al centro laboral, a la universidad, a la academia, a la escuela o a cualquier otro destino.

Así, lidiar con el encierro se hace imperioso en el bus, y en ese sentido el escape provisto por las ventanas deviene más que necesario y además preciso; suerte de válvula de escape para huir sobre la marcha, allende las fronteras físicas del bus. En ese sentido, mirar sin observar es cosa de todos los días, pero los nuevos tiempos proveen de nuevos recursos y posibilidades. Si primero fue la lectura de un diario o la de un libro, práctica en extinción en nuestro país, solo los ancianos hacen sudoku, la invención del walkman permitió llevar un concierto musical portátil y en ese sentido desplazarse en apariencia con mayor rapidez. Y es que la música nos hace discurrir más rápidamente, o mejor aún, acelera los tiempos muertos. Luego, la aparición del celular abre una nueva ventana para los usuarios, desde video juegos, videos, hasta lectura de diarios, pasando por el chat, Whatsapp, Facebook, Twitter, Instagram, por no hablar del uso primigenio, es decir, hablar con alguien. En todos los casos referidos subyace una característica común: el permanecer sin estar; ausentes por tiempo indefinido, los usuarios del bus precisan llenar los espacios y el tiempo para así generarse una existencia paralela.

Si el bus per se supone cuotas de aislamiento y en ese medida es menester buscar fugas y escapes, las nuevas tecnologías permiten sobrellevar, alivianar el peso del atiborramiento diario. Una joven adolescente asciende a la 87, no hay asientos, entonces se coloca sus auriculares, tararea la canción, golpea los pies sobre el piso, gira la cabeza, contornea su cuerpo; ella lleva un piercing en el ombligo y tatuado sobre la espalda, justo bajo el cuello, la frase Live with no regrets en cursivas. Sentado al lado de ella, pegado a la ventana, un hombre teclea con rapidez; luce escaso cabello y lleva 
lentes gruesos, sonríe, abre los ojos, visita páginas para adultos. De pronto se ve el descubierto, desde el bus de al lado dos muchachas lo han puesto en evidencia, sonrojado guarda el celular. Al fondo, un estudiante en uniforme escribe mensajes de texto y a ratos lee un texto escolar.

Lo anterior cobra sentido, toda vez que el bus solo posee una existencia vaporosa, de ahí que sea denominado tal cual lo haría Augé como un no lugar (Augé, 1992). Hablamos de un espacio flotante y público, lugar de encuentro para dinámicas sin compromiso, pero obligadas por la circulación acelerada de bienes y personas, para interacciones mínimas y roces máximos; el no lugar es pues un lugar de intercambio de lo inevitable, de lo forzoso transformado en rutina, lo casual como consensual, pues no lo olvidemos, el bus es extensión de la calle y, en un sentido más amplio, de la ciudad.

Volvamos a las ventanas, en general y casi a modo de regla, las ventanas en movimiento del bus dinamizan más la ciudad, lo que ahí acontece, proveen e insuflan de vida a algo aparentemente estéril, en virtud de su falta de novedad, todos los días se recorre las mismas calles y avenidas y, la postura en apariencia pasiva, el descansar arrellanado o permanecer inmutable de pie, transmite cierta desidia respecto a lo que circunda. Lo cierto es que viajar en bus termina siendo un ejercicio introspectivo deliberado e improvisado, suerte de necesidad para el encuentro de nuestra imagen corporal con lo más palpable de la ciudad o, en otras palabras, la conjunción y, en ese sentido, el resignificado de las ya clásicas delimitaciones entre lo interno y lo externo.

\subsection{Flâneur y voyeur}

Vayamos a la noción de flâneur. Recordemos que el flâneur es aquel que se entrega al paseo disperso cotidiano, suerte de extranjero en su propia ciudad (Joseph, 1988). El flâneur inmerso en el ritmo cadencioso de lo que aparece y desaparece en la calle; fijado dentro de un círculo espacial específico, cuya posición dislocada lo compele a incorporar cualidades que no provienen ni pueden proceder de ahí. 
Sin duda, el flâneur callejero recoge todo lo que a su paso encuentra y lo lleva al universo del bus y efectúa allí una suerte de mestizaje con lo que ahí ocurre. El resultado, una serie de dinámicas y configuraciones entre el medio de transporte, quienes lo utilizan y el flâneur que acaba de llegar.

A diferencia del flâneur, el voyeur se define por otro circulo de acción y más que aportar sustrae del lugar, pues lo que mira busca ser registrado en carne viva y no ser editado sobre la marcha (Freud, 1977). Sea a través de su propia mirada o vía el ojo tecnológico de un celular, en éste caso para una propia fruición a posteriori.

El mismo acto de contemplar lo que está aconteciendo ya representa la emoción y el goce mismos, así pues el atiborramiento del bus provee al voyeur la libre consumación de sus deseos, en virtud de la poca o nula distancia entre los cuerpos que va a maximizar las posibilidades de su universo contemplativo. En otras palabras, la conjugación del cuerpo y la estructura física del bus, abre un abanico de posibilidades novedosas para el voyeur, al someterse al encierro amplía su propio universo imaginario.

Así pues, el atiborramiento del bus lanza al voyeur a gestar sus propios intersticios y saturarlos con su mirada, el escape vía las ventanas del bus se torna estéril y el imperativo a crear las suyas aflora a flor de piel, se diría pues que él crea sus propios aglutinamientos al hacer zoom in sobre un área corpórea. El voyeur solo responde a su propia condición y circunstancia.

Un joven se encuentra sentado al lado izquierdo de una 45, cerca al conductor, la gente transpira, las ventanas abiertas, a los minutos sube una muchacha con falda blanca, se coloca de espaldas al muchacho, su cabeza está a la altura de los glúteos de ella, el material de su vestido deja ver el color rojo de su hilo dental, gira el cuello, da un primer vistazo y simula ver algo detrás, luego vuelve y recorre nuevamente su anatomía, golpea los pies y tamborilea los dedos sobre su pantalón. De pronto, una señora se levanta y deja libre un asiento de la derecha que será ocupado por la joven. El muchacho la sigue con la mirada, pero la posición de ella evita que él pueda ver más. El bus continúa su marcha y él mira hacia adelante, en el cruce de La Mar con Universitaria desvía su mirada hacia la puerta y visualiza un espejo rectangular justo 
frente al asiento de la muchacha. El vestido ceñido resalta su anatomía y lo delgado de su ropa interior también, no obstante, aquello reservado solo para ella queda al descubierto gracias a un espejo ubicado a una distancia prudente entre el pasajero sentado y los demás.

Afrontémoslo, el voyeur tiene el encuadre proporcionado por la altura exacta de los asientos o mejor aún, del objeto deseado a la altura de su mirada, glúteos, órgano femenino y busto. Si ellos están de pie, zonas erógenas particularmente inquietantes, pueden fantasear libremente con la visión que la mirada recorta, cuando no el espacio exacto entre su cuerpo y el de ella, la cercanía, la sensación de tocarla con la mirada, de imaginar un roce. Pero la reterritorialización de los espacios también juega a su favor (Deleuze, 2004). Parejas besuqueándose, el muchacho cogiéndola por el talle o ya en el límite, en los asientos de al fondo, realizando prácticas antaño reservadas para espacios más íntimos. Y por qué no, ver a un desconocido crear fricción sobre otro cuerpo y así estar a la par con el movimiento sincopado del bus y el impacto de los baches, de tal manera que el rebote del otro es el propio, el de uno mismo, el suyo.

\section{Personajes y sus performances}

\subsection{El mendigo}

En una ciudad como Lima la mendicidad en sus diversas formas está imbricada al ritmo cadencioso de la ciudad, a las variantes fluctuantes de necesidad, apariencia, gestualidad y performance.

Ahora bien, durante la observación, el mendigo promedio en las líneas 45 y 87 es adulto y adulto mayor, en su mayoría mujer y, según sus propias palabras, básicamente se dedican a esta labor precisamente porque carecen de empleo y más bien son los jóvenes quienes, solo en ocasiones, esgrimen alternar la labor de mendicidad con un trabajo paralelo formal o posibles estudios. Y a propósito de ello, el 30.6\% (2 millones 279 mil 300 personas) de la población en edad de trabajar es considerada inactiva, es decir, no trabaja ni tampoco busca hacerlo (INEI, INFORME TÉCNICO No 
5 Mayo 2016, Situación del Mercado Laboral en Lima Metropolitana). A su vez, en el 2014, la Población Económicamente Inactiva, integrada principalmente por amas de casa, estudiantes, jubilados, personas con algún tipo de enfermedad o discapacidad, alcanzó los 6 millones 272 mil 200 personas; de ellos, la tercera parte $(33,4 \%)$ son hombres y el 66,6\% mujeres. Por grupos de edad, el 46,4\% se encuentra comprendida entre los 14 a 24 años, el 31,9\% entre los 25 a 59 años, el 4,1\% entre los 60 a 64 años y el 17,5\% tiene 65 a más años de edad. Finalmente, el 35,5\% está conformada por estudiantes, entre los varones este porcentaje alcanza el 51,9\% y entre las mujeres el $27,2 \%$. Asimismo, el 45,0\% se dedica a los quehaceres del hogar, en los varones es el $16,9 \%$ y en las mujeres el $59,1 \%$. Por otro lado, 6,3\% es jubilado/pensionista, en los varones es el 11,6\% y en las mujeres el 3,6\%. El 12,4\% está enfermo o discapacitado; entre los hombres el 17,8\% y en las mujeres el 9,7\% (INEI, Perú: Evolución de los indicadores de empleo e ingresos por departamento, 2004-2014).

Los mendigos apelan al sentimentalismo que su propia condición exhala, esto es, la apertura a su universo viene vía la concretización de su circunstancia en forma de historia que contar. Fabular, luego, deviene fundamental en tanto interpelación al otro, cuyo objetivo se desliza de la experiencia personal al argumento de caridad por excelencia. En ese sentido, su mensaje discurre entre el bus y la audiencia, por eso es imprescindible contar con una unidad que se encuentre ni muy llena ni muy vacía, y al mismo tiempo esa suerte de inmovilidad de los ambulantes y desplazarse asiento por asiento con la mano extendida, acorta aún más la distancia entre el mendigo y el pasajero.

Pensar en los vendedores ambulantes del bus supone, por lo menos, una definición oscilante entre actor y performance. Y a propósito de los cómicos ambulantes se puede decir que, mucho más que actuar, ellos serían narradores orales de historias (Vich, 2001). Pues bien, en nuestro caso nos referimos a esa gradiente entre la historia autobiográfica y el desempeño de un papel, pudiendo estar amalgamadas, ceder su posta y ser retomadas al antojo de los vendedores y las circunstancias. En buena cuenta, es difícil determinar en qué medida la experiencia personal es transformada en personaje, en otras palabras, cuánto de la actuación desplaza a la biografía o cuánto de 
ésta prevalece sobre aquella. Recordemos que estamos hablando de desempeños y éstos se instalan en la caracterización, en la realización del engarzamiento o conjunción entre las expectativas de los involucrados y sus respectivos papeles.

La 45 acaba de reanudar su marcha, una señora trepa al vuelo, el chofer apaga la radio; cabello hirsuto teñido, chompa de lana, zapatillas blancas, pantalón de bolsillos anchos, tiene ojos grandes claros, piel blanca, rostro ovalado. "Señores, señoras y señoritas, jóvenes, me he visto en la necesidad de salir a las calles, mi hijito sufre de retraso mental (silencio) y yo tengo cáncer. Su padre nos abandonó hace ocho años y yo soy padre y madre para mi hijo, pido su colaboración, no me dé la espalda, por favor". Ladea la cabeza, hace un barrido rápido de izquierda a derecha, zoom in y zoom out sobre los rostros. Empieza a caminar y estira su bolsa, "se puede, se puede", pasa de asiento en asiento, el gesto adusto va en aumento, frunce el ceño, sus movimientos son rápidos. Ante la negativa de la audiencia murmura insultos para sí, para los demás.

Acortar la distancia entre los cuerpos y el espacio es un ejercicio constante y necesario. Se acercan y se separan, relación a todas luces simbiótica, favorecida por la fisonomía del bus, a fin de cuentas pretexto para dar pie a la enmarañada suerte de relaciones que ahí tienen lugar. Recordemos que el accionar de los hombres se percibe como el acto de llenado de un espacio, es decir, es recién cuando los involucrados entran en acción e interactúan que el espacio deviene corpóreo (Simmel, 1986). En otra clave, el espacio del bus solo cobra sentido en la medida que las dinámicas tienen lugar, a raíz de la interacción entre los interactuantes, son ellos quienes le dan solvencia a su existir, que aunque pasajero, sirve de plataforma para los desempeños y roles del caso.

\subsection{El delincuente}

Dentro del bus, el factor sorpresa y distractor juegan un rol fundamental. Nos referimos al delincuente que subrepticiamente se oculta entre el gentío; en realidad, se pierde, deviene un pasajero más. El carterista es tal precisamente porque los demás están obnubilados en sus quehaceres cotidianos, máxime si por estos tiempos, nadie tiene tiempo para nada o, en otra clave, le dedican tiempo a todo y en esa medida los 
sujetos se sujetan a los designios de la tecnología, recordemos que el bus es una invitación explícita, sino a la abstracción, por lo menos a perderse de uno mismo, al estar fuera de sí, he ahí precisamente la condición a la cual compele el enclaustramiento del viaje en bus, suerte de válvula de escape a la condición misma del viajero promedio.

Un joven se encuentra abstraído en su lectura, su maletín y lonchera a un lado, lleva saco, chaleco y corbata. Un hombre se coloca a su lado, deja caer monedas sobre él, el lector solo reacciona cuando el otro se acerca para recoger sus monedas y al hacerlo roza sus genitales, el afectado se sobresalta y abre las piernas. El hombre se aleja, el muchacho levanta la mirada y encuentra los ojos de un sujeto robusto en la puerta, siente una sensación rara, de confusión, los sujetos bajan al vuelo. Solo entonces el afectado repara en su celular, toca el bolsillo derecho de su saco, no siente nada, se sobresalta, mira hacia la calle, en una fracción de segundo recuerda el rostro, la casaca y las zapatillas del ratero. "Bajan, bajan" grita desesperado.

Así, todos son malhechores, todos son pasajeros, todos son pasajeros y delincuentes; es decir, por un lado, todos pueden ser pasajeros en la medida que se comporten como tales, viajeros estándar, usted, yo, el de al lado, el de atrás, el de adelante y, por otro lado, el que delinque en el bus, vía la modalidad de perderse en el gentío, de hacerse pasar por alguien más, de parecerse a o de minimizar las diferencias entre él y el resto; simplemente toma lo característico de cada uno, se apropia de ello, lo hace suyo y lo encarna; aunque, valgan verdades, de alguna manera simplemente cumple un papel dado socialmente.

\subsection{El mañoso}

Afrontémoslo, el viraje cultural de fines del siglo XIX, cuya materia prima encuentra solaz en el siglo $\mathrm{XX}$, ha visto el zénit de su apogeo, traducido en una sexualización de los sentidos, durante el desarrollo galopante de las comunicaciones o, tal vez, debido a éstas. 
Así, el ver se constituye como el penetrar en el alma del otro, radiografía externa que conduce a una interna; maximizar lo visto, el detalle, inmortalizar el instante vía su propia obsolescencia constante; la fruición del plano de detalle, el lente grano angular de la cámara que facilita lo recogido, asirlo y hacerlo a nuestra medida y antojo, he ahí la función de lo ocular en estos tiempos.

Se dirá que el encierro mismo potencia el ver, el ver sin ser visto, la metáfora del ocultamiento para mejor ver; el hecho es que ignorar el paisaje cuando no estrategia de enfrentamiento representa ir contra corriente con lo que se encuentra en boga en la actualidad, a saber: hallar, circunscribir y registrar lo que acontece ante nuestros ojos, merced a las nuevas tecnologías. Curiosamente, solo a través de ellas, esto es, a la posterior visualización de lo registrado, es que recién podemos ver el acto perpetrado. No es gratuito en ese sentido, la enorme cantidad de videos privados, tanto de contenido sexual como de interés público, que circulan a diario en los medios de comunicación; es la imperiosa dicotomía necesaria, por un lado, de dejar verse, de mostrarse y, por otra, de ver, de quitar el velo a lo oculto, a lo más recóndito; en ambos casos subyace el siguiente adagio, a mayor privacidad develada, aumento de interés $\mathrm{y}$, por tanto, incremento en la avidez de obtener más.

En nuestro caso, las posiciones, las distancias y las alturas provistas por el bus, conjugada o no con la tecnología, dan pie al intercambio de miradas, goce visual y, de darse el caso, registro selectivo para su posterior disfrute. Pero lo visual se diluye merced al encierro connatural al cual se entregan los lujuriosos del bus, lo que representa doblegamiento para otros, para ellos en cambio es acogido y cogido con furor; así, se pasa de la vista al tacto, al roce, del ver al sentir, pero siempre pasando desapercibido, sin que la víctima note algo inusual; he ahí tal vez la frontera de su placer, no poder gritarlo o, en todo caso, exacerbarlo hasta el mutismo, lindarlo con la propia inmovilidad que supone la movilidad del otro, esto es, excederse en las propias fantasías que el rozar la anatomía de la víctima despierta y desborda en él. 
El movimiento sincopado del bus duplica y encaleta las acciones subrepticias. Un joven de cabello hirsuto, jorobado, jeans sucios, zapatillas negras y polera holgada se introduce, murmura para sí palabras inteligibles, se coloca al lado derecho, luego al izquierdo, el volumen de la radio está al máximo, los asientos queman, la gente agita lo que tiene a la mano, los cuerpos sudan, las mujeres llevan blusa, polos manga cero o tops. Se coloca al lado de una muchacha blanca, delgada, cabello y ojos marrones, lleva anteojos, blusa clara y pantalón oscuro; el cierre del pantalón justo a la altura del hombro de ella, ha colocado estratégicamente un folder que cubre desde su cintura hasta la oreja derecha de ella y evita así ser descubierto. La víctima mira distraída hacia afuera, el otro baja su cierre y empieza a hacer fricción contra su hombro, ella continua abstraída hasta que siente algo húmedo, roza su mano y nota una sustancia extraña, levanta la mirada y ve al muchacho in fraganti. "Vete allá" le grita y señala un asiento al otro lado, "váyase allá", el otro camina encorvado, arrastrando los pies

Recordemos que Lima ocupa el tercer lugar en el ranking de las ciudades cuyo transporte público se evidencia como el más peligroso para las mujeres. El primer lugar lo ocupa Bogotá y el segundo Ciudad de México (Thomson Reuters, 2014).

Así, en la práctica se trata de minimizar los espacios aún más y maximizar el aglutinamiento, aprovecharlo al máximo; al elegir una posible víctima, ésta deviene un cuerpo dócil, fragmento o parte del todo, hombre o mujer, aunque valgan verdades, casi siempre son los hombres los perpetradores, la anatomía de ella es reducida a una porción que represente el todo, el talón, el empeine, las pantorrillas, los glúteos, los muslos, el busto o el cuello. De pie, la cámara del ojo registra en picado el nacimiento del seno y posiblemente la zona baja lumbar y consecuentemente la ropa interior que escapa; sentado prioriza en contrapicado, los pocos secretos que los pliegues de la piel adheridos al vestido ocultan, los misterios del color y las formas femeninas, la tetamenta en plano general. 


\subsection{El viajero estándar}

De pie o sentado, cómodo o incómodo, masculino o femenino, joven o anciano, dormido o despierto, el viaje en bus representa una explosión sensorial y cognitiva. Cierto es que las más de las veces es un suplicio y que la mayoría preferiría desplazarse en taxi o en carro particular, sin embargo, el viajero promedio se repantiga en el asiento, se deja estrujar, se pierde entre el gentío, descubre nuevos límites espaciales.

Por un lado, la movilidad del bus supone adentrarse, sin proponérselo, en una dimensión paralela, interna; de una muchedumbre enclaustrada pasamos a un conjunto de individuaciones. El viaje en bus, valgan verdades, conlleva a cuotas inerciales cuando no soporíferas, pero el movimiento externo induce, inconscientemente, a un observar, a un ensimismamiento en la dentrura cotidiana de cada uno, a un extraviarse y por qué no, escaparse y penetrar en una espacialidad distinta, tanto temporal como de lugar. Sensación de no saber si es la ciudad la que se mueve o el efecto motriz connatural al vehículo; impacto inercial en el cuerpo al viajar, tanto en el desplazamiento como en la parada.

Son las 7:30 am, la 87 abandona su paradero completamente vacía, los primeros madrugadores se desplazan de asiento en asiento, buscan el adecuado, una vez hallado se sientan e inmediatamente estiran piernas y brazos, duermen entre 20 a 40 minutos, otros suben en la avenida Cuba, el carro ya está lleno, en la mano llevan una bolsa blanca, adentro quinua, maca o moliente acompañado de un par de panes, han abandonado el hogar con el estómago vacío. Otros, los que ya están sentados, sobre todo mujeres, sacan avena con leche de su bolso y pan con mantequilla o jamón. Los caballeros son más prácticos, aunque no es exclusivo de ellos, beben bebidas energizantes, gaseosa o jugo en caja, comen queques, galletas o waffers. 
Avenida Abancay, 8:00 pm, sábado, un universitario monta la 45 a la altura de la avenida Salaverry, se recuesta en los asientos de al fondo, al lado de la ventana, levanta los pies y los apoya sobre la barra que sirve de pasamanos, antes de cruzar Arequipa ya fue vencido por el sueño, los auriculares penden de sus orejas. Al llegar a la avenida Abancay se levanta aletargado, se quita las gafas y se soba los ojos, abre su mochila y extrae un táper lleno de arroz chaufa, mientras engulle cada bocado observa el Centro Comercial el Hueco, símbolo de la informalidad institucionalizada en el centro de la ciudad, al llegar al Congreso de la República guarda su cuchara, han pasado exactamente quince minutos desde que dio el primer bocado. En un día promedio los pasajeros se encuentran sumamente cansados, agotamiento reflejado en sus rostros, ojeras hondas, cabello desordenado, ropa sin planchar y sucia. A derecha e izquierda, los dos primeros asientos son de distinto color, están reservados para el adulto mayor, la mujer embrazada, para el que lleva un bebe en brazos y para aquel que ha sufrido alguna lesión o posee alguna discapacidad, tal cual lo indica la calcomanía sobre ellos y las palabras Asiento Reservado. De tal manera que quede claro la importancia de, por lo menos disponer de mensajes que refuercen el recordatorio, y ya no necesariamente de poner en práctica las prácticas que el bus alienta.

Una señorita en falda corta se eleva sobre los peldaños, una lonchera y un bolso cuelgan del brazo, viste traje de secretaria, su cabello luce milimétricamente ordenado, ha pintado sus uñas y sus labios con cuidado, lleva rubor y perfume abundantes, mira de reojo a los asientos más próximos, eleva sus bultos de tal manera que no pasen desapercibidos, especialmente por los varones, en cuestión de segundos un caballero le ofrece el asiento.

Cuando los asientos reservados están ocupados se espera que algún pasajero se solidarice y se ponga de pie. Un padre de familia sube con su hijo en brazos, los asientos reservados están ocupados, detrás de ellos dos jóvenes escuchan música, una mujer con el ceño fruncido mira de reojo y un hombre pretende dormir o mirar a través de la ventana. El papá aguarda pacientemente, la señora de al lado evita mirarlos, mastica chicle y tuerce la boca, el hombre de la ventana tiene el cuello encorvado, mira 
la pantalla del celular, detrás de él lo mismo, dos adolescentes conversan y ríen, por momentos miran y continúan su conversación. A los diez minutos un pasajero sentado en la mitad del bus se alza y le ofrece el asiento.

\section{Delimitando campos de acción}

\subsection{Callao city}

La provincia del Callao cuenta con más de 900 mil habitantes, en Bellavista, en La Perla y La Punta predomina el sector B, en el distrito del Callao y Carmen de La Legua el $\mathrm{C}$ y en Ventanilla el E, el más pobre de Lima metropolitana y el que más ha crecido en la última década (EMPRESA EDITORA EL COMERCIO S.A., 2007).

A la población propiamente del Callao se le identifica por el vestir, por lo general tonalidades grises, pero también abigarradas, el mirar saltón, el cabello grueso y el color bronceado de piel. Los chalacos de pura cepa no abandonan el Callao, pues tienen todo a la mano, supermercados, su mercado, su cine, El Porteño, su fortaleza, El Real Felipe, su teatro, El Municipal, su diario, aunque de tiraje menor, su playa, su propia cerveza y su equipo de fútbol, el SBA.

El Callao es puerto y tal vez por eso la idiosincrasia del chalaco sea, por naturaleza, bochinchera, avezada; los adultos mayores, los jóvenes y los adultos transpiran eso y las líneas 45 y 87 recogen sus particularidades y las esparcen a lo largo de su trayecto. Recordemos que un acto de oralidad es un evento social cuyo significado es resultado no solo de las relaciones internas del lenguaje, sino de la relación entre éstas y la realidad social que dio lugar a aquellas (Vich, 2001).

Es decir, la puesta en práctica de un lenguaje no solo está inmersa en la urdimbre de la socialización como mera funcionalidad y en esa medida influenciada por ésta, sino también funcionaría como vehículo transmisor cultural de los usos y desusos de los usuarios y de esa manera creando posibilidades, no previstas, en el corazón mismo de la interacción. 
La urbe, valgan verdades, escapa a los controles policiales, civiles; suele ser, sobre todo en algunos guetos, tierra de nadie y bronca de todos (Hevia, 2008). Tal cual una guerra de guerrillas, ocurren retrocesos y avances, luchas y contenciones, ganadores y vencidos. Y aunque la delincuencia ha crecido exponencialmente en los últimos años en Lima, los departamentos con mayor percepción de inseguridad son: Cusco (95,7\%), Tacna $(95,1 \%)$, Huancavelica (94,2\%), Madre de Dios y Arequipa (93,8\%), Provincia Constitucional del Callao (93,7\%), Cajamarca (93,2\%), Lima (92,9\%), Lambayeque (92,4\%), Ucayali (92,2\%), Puno (92,0\%), La Libertad (89,9\%), Apurímac (89,7\%) у Junín (89,6\%) (Informe Técnico - Estadísticas de Seguridad Ciudadana $\mathrm{N}^{\circ}$ 03: Setiembre 2016, INEI). No es gratuito en ese sentido, que en la mayoría de crónicas policiales aparezca el Callao como escenario predilecto de los crímenes registrados en la ciudad, tampoco el estado de emergencia declarado por El Poder Ejecutivo producto de la ola gansteril $\mathrm{y}$, por si fuera poco, la impunidad y el libre accionar que los implicados encuentran por esos lares, incluso a pesar de esa situación. Se trata en buena cuenta de un recrudecimiento de la actividad delictiva a raíz de un mayor control policial, de ahí que cobre sentido entonces, el adagio que a la letra reza que el chalaco es caliente y faltoso por antonomasia.

Barrio salsero por excelencia, el Callao es reconocido por Hector Lavoe, El Gran Combo, Niche, Willie Colón o Celia Cruz y más y es el barrio que más se ufana de tener personalidad "achorada", público faite, gente brava y de harto sabor popular (Empresa Editora El Comercio S.A., 2007).

Basta revisar los innumerables informes de Frecuencia Latina, América televisión, Panamericana Televisión y ATV, que dan cuenta de la inseguridad en el primer puerto, para comprobar que el alcalde confiesa no contar con los efectivos policiales suficientes, mientras que el jefe policial de la región Callao afirma una mejora desde la declaración de estado de emergencia, toda vez que, según él, antes de éste mataban quince personas, ahora solo ocho, el ciudadano de a pie, sin embargo, no percibe lo mismo. 
De la urbe nos deslizamos al bus como Pedro en su casa y los operarios del crimen también, y aunque a una escala menor, ellos hacen de las suyas, remontan de a dos, de a tres, bloquean las puertas y cogotean a todos los presentes sin tapujos ni miramientos, los pasajeros no tienen más remedio que acatar sus órdenes, el chofer y el cobrador se lavan las manos. Se habla de complicidad, de colusión, de libertinaje, el caso es que los delincuentes tienen total impunidad y libertad para cometer sus fechorías. También es cierto que la mendicidad es una forma de subsistir en la capital y en todos los buses también suben vendedores de golosinas y productos varios, así como hacedores de historias reales o inventadas. Pero la afluencia tanto de los primeros como de los segundos es mayor en las líneas 45 y 87 . Es más, hay transeúntes que evitan tomar dichas líneas para evitar tener que lidiar con las circunstancias mencionadas, léase ser persuadido de colaborar u obligado a vaciar la cartera, pero el asiduo usuario ya sabe que esperar.

- Yo nunca me siento atrás - le dice un joven a su compañero.

- ¿Por qué no?

- Es que ahí, en esa parte, siempre roban.

Cuestión de dimensión dirán algunos, los pasillos de dichos buses son largos y con eso mayor posibilidad de obtener ganancias. El metal resalta, pasamanos y asientos corroídos por los años, el motor retumba en medio del tráfico, los parlantes dejan escuchar música criolla, sobre todo a mediodía, y también salsa y eso tampoco es gratuito. En el año 1986 llegó Hector Lavoe al Perú y dio apoteósicos conciertos, pero la leyenda se extendió también a sus noches de farra en el corazón del Callao y a propósito de eso, en el barrio de Loreto y Atahualpa y Venezuela, tres de los lugares más peligrosos del Callao, lugar predilecto del mundo del hampa, un mural dedicado a los salseros duros decora el lugar, en la esquina de la cuadra 3 del jirón Atahualpa Hector Lavoe, Tito Puente, Frankie Ruiz y Celia Cruz se erigen como santos patronos. El artífice, Alexis Villanueva, el salsa, cuenta en una entrevista para el diario Ojo, que los vecinos le pidieron repitiera lo que hiciera en Puerto Nuevo en el 1996, es así que lo volvió a hacer en el 2001, pero además incluyó a las víctimas de la violencia exacerbada por esos lares, al igual que el otrora muro que Philippe Bourgois menciona 
en su estudio sobre el crack en Harlem, a saber, un graffiti en memoria de los caídos producto de la violencia callejera de Nueva York, cuya función no se aleja de normalizar las matanzas públicas (Bourgois, 2010).

Es cierto que hay una clara diferencia entre asesinar personas en plena vía pública y robar en buses, de eso no hay duda, sin embargo, el Callao, sus buses y su gente exhala un clima beligerante connatural. Tres datos más, la 45 va lenta y a diferencia de otras líneas no parece competir, y es larguísima, semejante a los buses escolares, y llega a los penales Lurigancho y Castro Castro, de hecho su paradero final está a unos minutos después de ellos.

La 87 sale de Chucuito, al frente del colegio Dos de Mayo, el aroma de la pleamar cubre esa parte del litoral, son las 7:30 de la mañana y las casitas de maderas de colores se asemejan a las de la Boca, barrio también picante en la Argentina; música nueva ola se deja escuchar por los parlantes, el bus se mueve despacio, sin apuro, a las 7:40 Los embajadores criollos y a las 7:45 Gaby Zevallos suenan por los parlantes. De espaldas al conductor un vinilo gigante lleva impreso al ídolo salsero Frankie Ruiz, ya inmortalizado en algunos muros chalacos.

Viajar del Callao hasta San Juan de Lurigancho toma tres horas, la gente duerme en las mañanas y en las tardes también, regresar a casa agota. Sobre el atardecer del Callao se ven los barcos flotar sobre el muelle, en la calle José Gálvez, La Perla, hay un mural dedicado a Jesucristo, policías en las calles, cinco amigos y una caja de cerveza en el medio, cerca al Alipio Ponce Vasquez, dependencia policial, un grupo juega cartas en una carretilla. La mayoría de casas del Callao son pequeñas y de material noble, de un piso o dos, con rejas en las ventanas y en las puertas.

Una mujer con un bebé y dos niños son encaramados en la avenida Buenos Aires, presurosos se desparraman atrás en lugares separados, llevan un coche y bolsas con ropa y botellas recicladas. Ella calma el llanto de la criatura con leche materna. Dos sujetos suben a la altura de la Municipalidad de Bellavista. Ellos la saludan, chocan sus puños con los de ella. "Ése es mi hijo" le dice a su compañero mientras señala al lactante, "como hablas conch..." responde la supuesta mamá, "pero así eres tú" agrega él. Se abre la puerta y pisan afuera rápidamente, “calla basura de mi..." le dice ella. 
Asciende una mujer por la puerta trasera y desciende por ahí mismo, bajo el rotulo bajada, al lado una flecha indica un botón y sobre ella la palabra timbre, en la parte de atrás, un asiento de diferente color al lado de la puerta trasera, de espalda a la ventana, las gentes se apegan y se despegan. Otra asciende por la puerta delantera, subrepticiamente el chofer cierra la ubicada detrás en las narices de un pasajero. Los taxistas, custers y combis se agolpan a la derecha, de tal manera que la 87 debe torearlos, virar sinuosamente, alejarse, se desplaza en zigs zags, luego en línea recta. Normalmente el pasajero que está cerca a la puerta utiliza ésta para enclaustrarse o liberarse del bus, pero en ocasiones ocurre que el chofer o el cobrador exigen se respeten las reglas, esto es, llegar a la calle por atrás y librarse de ella por adelante.

Podríamos llamar a lo anterior un devenir de naturaleza rizomática, ir más allá de los binarismos, libres de toda dicotomización. Allende pues de las máquinas binarias, quebrando la estructura, la diferenciación y que más bien dan saltos entre línea y línea, entre seres que nada tienen en común (Deleuze 1997). Lo opuesto a lo arborescente, en la medida que conecta puntos dispares y a su vez cada característica no remite necesariamente a rasgos de la misma naturaleza. Así pues, el rizoma no tiene ni inicio ni fin, su propia naturaleza desborda, pues no es la unidad lo que prima en él, sino las múltiples dimensiones compuestas de líneas de diversas dimensiones, de ahí que tampoco sea una estructura, pues ésta supone algo fijo, biunívoco. Naturalmente, tal unidad no está exenta de mutar, todo lo contrario, su propio origen y características la compelen hacia la transformación constante.

La luz natural de la mañana penetra los espacios del bus, el desayuno descansa en el estómago, es devorado sobre la marcha o es llevado dentro de una bolsa. La gente está junta, apretada, contigua, el espacio físico es casi irreductible entre uno y otro pasajero, pero cada uno vive e imagina su periplo, las paredes del bus los obligan a compartir una extraña contigüidad, pues a su vez cada uno se aísla del trayecto, sea con los audífonos, leyendo, durmiendo, comiendo o simplemente divagando, se despistan aun cuando el bus no lo haga. Son las 8:00 y suena Hildemaro, cuando parece que ni una sola persona más cabe en el espacio reducido, de pronto se agrega alguien más. 


\subsection{Lima Centro}

Lima Centro está conformada por los distritos de Lima (Cercado), Rimac, Breña, la Victoria y San Luis, su población bordeó el millón de habitantes en 1980, pero desde entonces demográficamente ha decaído. Actualmente residen en ella alrededor de 800 mil habitantes, la mayoría de nivel socioeconómico $\mathrm{C}$, y aún se mantiene el centro de la actividad comercial y de esparcimiento de los limeños, pero más de los nuevos limeños que de los antiguos, así como migrantes o hijos de inmigrantes (EMPRESA EDITORA EL COMERCIO S.A., 2007).

El Centro de la ciudad siempre ha sido lugar donde confluyen el migrante, el que pasea, el que va de compras, el que vive en su perímetro, el que acude estrictamente por razones laborales y aquel que lo hace solo por divertimento. Ya desde los años ochenta, el Centro de la ciudad era conocida por sus aglomeraciones, informalidad, transporte público y delincuencia, situación que no parece haber cambiado.

En efecto, según el informe Observatorio Lima Cómo vamos, la mayoría de encuestados menciona el Centro de Lima como lugar predilecto. Ante la pregunta cuál es el distrito al que se dirigen principalmente para trabajar o estudiar, el Cercado de Lima terminó en primer lugar, formando así un (14.5\%), San Juan de Lurigancho (8.1\%), Santiago de Surco (6.4\%), Miraflores (5.9\%) y San Isidro (4.7\%) (Evaluando la Gestión en Lima: Sexto Informe de Resultados sobre Calidad de Vida, 2015).

A su vez, según el portal mapcity.com, las calles más saturadas de la capital son la avenida México y la avenida Abancay, sobre todo en horas punta toma alrededor de 30 minutos recorrerlas, ya que $27 \%$ de las rutas autorizadas transitan diariamente por ellas, es decir, hasta 50 rutas de transporte (Mapcity.com, 2016).

Sin lugar a dudas la avenida Abancay ha sido desde los ochentas una arteria vial emblemática, referente obligado para el paseante, el comerciante, el limeño promedio, el curioso. Asimismo, las líneas 87 y 45 no solo representan dos de los buses más antiguos aún vigentes en Lima, sino que además, lo variopinto y extensión de sus rutas, su periplo abarca desde el corazón del Callao hasta San Juan de Lurigancho, cruzando La Perla, San Miguel, la avenida Faucett, Pueblo Libre, Jesús María, Lince, la avenida 
Cuba, la avenida Arenales, la avenida Arequipa, la avenida Petit Thouars, La Vía Expresa, La Victoria, la avenida Abancay y más allá, transforman los buses en extensión de los distritos o en laboratorio mismo de sus habitantes y sus particularidades.

Cabe resaltar que tanto el Callao como El Centro comparten la idiosincrasia animosa y el espíritu vivaracho de sus gentes, así como la informalidad y el carácter tradicional de sus costumbres, hecho plasmado a lo largo y ancho de su paisaje y arquitectura.

Al lado izquierdo de la avenida Abancay el parque universitario, la insigne Casona de San Marcos con su Big Ben peruano y sus mesas de ajedrez; al frente el antiguo edificio del Ministerio de Educación y al lado derecho, justo de cara a éste, el Centro Comercial el Hueco y al fondo, Paruro. Transversalmente cruzada por el Mercado Central, El Jirón de la Unión, El barrio Chino y Mesa Redonda, ella y sus alrededores son referentes obligados de lo que podríamos llamar buena parte de la cultura limeña; la fluctuación constante entre lo cotidianamente informal, lo colorido, lo atiborrado, lo comercial y lo peligroso del lugar; lo tradicionalmente institucionalizado de todo lo anterior.

La gente cruza entre los intersticios que dejan los autos, la luz está en rojo, luego cambia a verde y vuelve a rojo y todo empieza de nuevo; para el caso da igual, pues si el tráfico está detenido o es lento, los peatones de todos modos hacen de las suyas. A veces se apuran y aceleran el paso, de tal manera que fallan al calcular el tiempo del siguiente semáforo, no tienen más remedio que detenerse y esperar en medio de las dos pistas, rodeados de más transeúntes, taxis, colectivos, custers, combis, buses, carros interprovinciales, ambulantes y ciclistas que diariamente recorren ese trayecto.

El paradero de la 45 está en un cerro y a veinte minutos de su salida, el siguiente dialogo tiene lugar. 
- Podemos ir a Acho y dar la vuelta - dice el chofer de las 45.

- O seguimos, depende de usted, pero el tráfico en Caquetá es terrible - agrega el cobrador.

La mujer los escucha en silencio. Afuera una carretilla llena el bus de huaynos, la puerta se dobla y trepa un vendedor con un parlante y un micrófono portátil, el ruido interno y externo evitan que su discurso sea claro, más gente llena el bus, el sujeto no tiene otra opción que guiarlos e indicarles los asientos disponibles, luego prosigue con su explicación; ninguno de los concurrentes compra exprimidores de limón de plástico a dos soles. A los cinco minutos otro lo secunda y raudo empieza a predicar, el primero aún está en el bus, se ha sentado y lo observa a la distancia.

El ruido, luego del tráfico y los atiborramientos, es una característica saltante del Centro de la ciudad y, desde luego, también de la avenida Abancay. Según el informe La contaminación sonora en Lima y Callao del Organismo de Evaluación y Fiscalización Ambiental (OEFA), los núcleos identificados con valores críticos en cada zona geográfica de Lima son en Lima Centro, en el distrito de Breña; en Lima Este, en los distritos de El Agustino, Ate, San Juan de Lurigancho y Lurigancho Chosica; en Lima Norte, en los distritos de Comas, Carabayllo y San Martin de Porres; y en Lima Sur, en los distritos de San Juan de Miraflores y Villa María del Triunfo. El informe agrega, además, que en general, la principal fuente generadora de ruido que se identificó en la mayoría de los puntos de medición fue el tránsito vehicular (transporte público y privado y uso de bocinas) que se presenta en horas punta (OEFA, 2016).

Hay que agregar, además, que en el cruce de Abancay y Cuzco hay institutos, vendedores ambulantes pregonando sus mercancías y tiendas de electrodomésticos cuyos ruidosos parlantes son colocados en las veredas para atraer clientes.

Volviendo de San Juan de Lurigancho al Callao hay demasiada congestión, son casi las 12 pm y a la altura de Caja de Agua unos bloques limitan el acceso a un carril, el copiloto de una camioneta baja y mueve uno de los mojones, dejando el camino libre, algunos autos se animan y toman el nuevo atajo. 
Unos metros más allá un mural exhibe a Hector Lavoe, Celia Cruz y Willie Colón, igual al del Callao; al lado de él una iglesia, al frente, en la otra vereda, una imagen de Jesús y un mensaje.

Los cruces son invadidos, en rojo se avanza, en verde todo es estático, pero también pasa que en rojo discurre el tráfico y en verde se paraliza. La idea es seguir al de adelante, el desplazamiento ondulatorio de los otros.

A la una de la tarde y en plena Plaza de Acho, el tráfico vence a la 45, devuelven el pasaje e invitan a tomar otro bus.

De noche uno podría pensar que todo desaparece en la avenida Abancay, lo cierto es que disminuye la afluencia de gente en las pistas y veredas, pero solo para dar paso a meretrices y sus respectivos controladores, un vendedor de paltas en carretilla grita "paltas para el desayuno", algunas parejas, las tiendas en la hilera del Centro Comercial el Hueco están iluminadas con fluorescentes, flâneurs nocturnos, vendedoras de fritangas, personas con paquetes, las veredas y las pistas lucen despejadas, ahora es más fácil reparar en la basura acumulada.

Dentro del bus un vendedor ofrece billeteras estampadas con el diseño de un billete 100 dólares, 100 y 200 soles, billetes de la India e Inglaterra. De pronto, un niño grita, quiere miccionar, la madre le dice que espere, ya falta poco; pasan unos minutos, no puede más, los pasajeros se solidarizan y le alcanzan una bolsa;

El retorno a través de la avenida Abancay es más rápido, la noche ha dado paso a una iluminación cálida, rojiza, y a su vez ésta dará paso a una nueva, noctámbula, y posteriormente a las luces del nuevo día. 


\section{CONCLUSIONES}

Los espacios físicos del bus se reconfiguran según las circunstancias, sensibilidades y necesidades de los pasajeros y de los personajes, de acuerdo a los usos que ellos precisen hacer de él, sea de manera premeditada y consensuada, sea de manera espontánea y como parte de una dinámica que va más allá de todo orden, control y aparato regulatorio.

Lo performativo de los actores del bus se define por el carácter étnico y geográfico de procedencia, sus expectativas se depositarán a través del lenguaje particular usado y acorde con los límites y caracterizaciones del caso que sus territorios de origen los lleven a poner en marcha, ora para lograr una reacción específica, ora para sortear una situación.

El bus es una extensión de la calle, ésta se introduce, se refleja y reverbera en él, se remedan, se copian y, a su vez, el resultado de esa transformación regresará de vuelta y en ese devenir las prótesis creadas sobre la marcha, los duplicados callejeros, devendrán parte o todo, es decir, eventualmente reemplazaran a la calle misma, para luego dar paso al mismo proceso una y otra vez, aunque siempre con cuotas novedosas.

La cuestión étnico geográfica juega un rol relevante en la interacción al momento de definir sus características, sin embargo, no es determinante en el contexto comunicacional del bus, de hecho, cuestiones surgidas en el trayecto mismo bien podrían diluir los lugares comunes y dar lugar a nuevas formas de socialización, en mayor o menor medida, libres de categorización. 
El encierro físico del bus hace las veces de prisión, obligando así a sus usuarios a elaborar técnicas escapistas o a hacer uso de las nuevas herramientas tecnológicas para la consecución de un escapismo efectivo, si antes fue la lectura de diarios y libros y escuchar música, en este caso particular el celular y, más precisamente, las redes sociales y el Whatsapp apuntan a ese propósito.

Si bien es cierto que el bus facilita la introspección, el mutismo, desinhibirse y hasta la animadversión, no obstante, nuevas formas de interacción y un nuevo flujo comunicativo se dinamizan, toman nuevas rutas, se construyen y se deconstruyen sobre la marcha de manera continua, a partir del propio encierro, su propia condición y lo surgido del momento.

Es precisamente la configuración de los espacios y la naturaleza del bus, así como el conocimiento de esas circunstancias por parte de los usuarios y los personajes, aquello que favorece el camuflaje y el reinventarse constantemente, en otras palabras, el bus hace las veces no solo de puesta en escena para hacer efectivo un marketing callejero, sino también un teatro en movimiento. 


\section{REFERENCIAS}

AUGÉ, Marc

1992 Los no lugares. Espacios del anonimato. Una antropología de la sobremodernidad. Barcelona: Gedisa.

BENJAMIN, Walter

$2005 \quad$ Libro de los pasajes. Madrid: Ediciones Akal, S.A.

BERMAN, Marshall

1988 Todo lo solido se desvanece en el aire. La experiencia de la modernidad. México D.F.: Siglo XXI editores, s.a.

BOURGOIS, Philippe

2010 En busca del respeto: vendiendo crack en Harlem. Argentina:

Siglo Veintiuno Editores Argentina S.A.

CÁNEPA, Gisela

2011 Imaginación visual y cultura en el Perú. Lima: PUCP.

DE CERTEAU, Michel

2000 La invención de lo cotidiano. I Artes de hacer. México D.F.:

Universidad iberoamericana.

DELGADO, Manuel

1999 El animal público. Hacia una antropología de los espacios

urbanos. Barcelona: Editorial anagrama.

ECHECOPAR, Charo

2012 Oficios a la Limeña. Lima: Publisher.

EMPRESA EDITORA EL COMERCIO S.A.

2007 Lima Capital. Estilos de Gran Urbe. Lima: Empresa Editora El Comercio S.A.

FOUCAULT, Michel

2006 Seguridad, territorio, población. Buenos Aires: Fondo de Cultura Económica. 
FREUD, Sigmund

1977 Volume 7 On Sexuality. Three Essays on the Theory of Sexuality and Other Works. London: Penguin Freud library.

GILLES Deleuze

1997 Diálogos. Valencia: Pre-textos.

GILLES Deleuze

2004 Mil mesetas: Capitalismo y esquizofrenia. Valencia: Pre-textos.

GOFMMAN, Erving

2012 Estigma: La identidad deteriorada. Buenos Aires: Amorrortu editores.

JOSEPH, Isaac

1999 Erving Goffman y la microsociología. Buenos Aires: Gedisa.

JOSEPH, Isaac

1988 El transeúnte y el espacio urbano. Buenos Aires: Gedisa.

HALL, Edward

1963 Proxemics: The Study of Man's Spatial Relations and Boundaries. New York: International University Press.

HEVIA, Julio

2008 Habla jugador. Gajes y oficios de la jerga limeña. Lima: Taurus.

INEI

2015 Perú: Evolución de los indicadores de empleo e ingresos por departamento, 2004-2014.

INEI

2016 Informe técnico No 5 Mayo 2016, Situación del Mercado Laboral en Lima Metropolitana.

LIMA CÓMO VAMOS

2015 Evaluando la Gestión en Lima: Sexto Informe de Resultados sobre Calidad de Vida 2015.

LYOTARD, Jean Françoise

1988 La Condition Postmoderne. Rapport sur le savoir. Paris: Éditions de Minuit. 
OEFA

2016 Informe de La contaminación sonora en Lima y Callao.

Organismo de Evaluación y Fiscalización Ambiental (OEFA), 2016.

MANGIERI, Rocco

2006 Tres miradas, tres sujetos. Eco, Lotman, Greimas y otros ensayos semióticos. Madrid: Biblioteca nueva.

\section{MAPCITY}

$2016 \quad$ wwww.mapcity.pe

SIMMEL, Georg

1986 Sociología 2. Estudios sobre las formas de socialización. Madrid: Alianza Editorial.

TESTINO, Mario

2007 Lima Peru.Bologna: Damiani.

VICH, Victor

$2001 \quad$ El discurso de la calle. Los cómicos ambulantes y las tensiones de la modernidad en el Perú. Lima: PUCP. 